\title{
Photo-illuminated Glutathione Inactivates Alpha-2-macroglobulin: Spectroscopic and Thermodynamic Studies
}

\author{
Syed Saqib Ali ${ }^{1}$, Haseeb Ahsan², Sana Ansari ${ }^{1}$, Khan M Abdullah¹, Fahim Halim Khan \\ ${ }^{1}$ Department of Biochemistry, Faculty of Life Sciences, Aligarh Muslim University, Aligarh, India \\ ${ }^{2}$ Department of Biochemistry, Faculty of Dentistry, Jamia Millia Islamia, New Delhi, India
}

Background: Glutathione (GSH) is a principle thiol-containing tripeptide (cysteine, glutamic acid and glycine) antioxidant against free radicals and other harmful oxidants in cellular defence. The alpha-2-macroglobulin $(\alpha 2 \mathrm{M})$ is large tetrameric zinc-binding glycoprotein which inhibits proteinases regardless of their specificity and catalytic mechanism.

Materials and Methods: The interaction of GSH with $\alpha 2 \mathrm{M}$ including the structural and functional alterations were analyzed using various biochemical and biophysical methods. UV-visible and fluorescence spectroscopy were used to study the binding of $\alpha 2 \mathrm{M}$ with GSH and Fourier transform infrared (FT-IR) spectroscopy was explored to study the structural change induced in $\alpha 2 \mathrm{M}$.

Results: The results suggest that exposure of $\alpha 2 \mathrm{M}$ to GSH decreases the antiproteolytic potential as suggested by the amidase assay. The UV-spectroscopic study showed the formation of a2M-GSH complex and fluorescence analysis showed significant quenching in fluorescence intensity of $\alpha 2 \mathrm{M}$ suggesting GSH binding and structural alteration in the protein. FT-IR spectroscopy was explored to study the structural change induced in $\alpha 2 \mathrm{M}$ which suggest that the secondary structure of a2M changes upon complex formation.

Conclusion: Our studies show that interaction of $\alpha 2 \mathrm{M}$ with photoilluminated GSH results in functional and conformational changes in the protein.

Keywords: glutathione, GSH, alpha-2-macroglobulin, photo-illumination, ITC, FTIR

\section{Introduction}

Glutathione (GSH) is a low molecular weight cellular antioxidant and has various enzymatic and nonenzymatic properties. ${ }^{1}$ In the human body, GSH is present as ubiquitous molecule i.e., produced in all organs. The main function of the GSH in the human body is to maintain the integrity of red blood cells (RBCs). It is a tripeptide antioxidant mainly found in two forms: reduced GSH and oxidized glutathione (GSSG). ${ }^{2}$ Among the two forms, GSH is mainly found in healthy living cells $(90 \%)$ while GSSG occurs in minor amount $(10 \%)$ in cells. ${ }^{3}$ It is mainly found in millimolar $(\mathrm{mM})$ concentration inside the cells, while the plasma contains lower amount of GSH. ${ }^{4,5}$ In cells, GSH may be found

Date of submission: September 22, 2021 
freely or bound to proteins. As a radical scavenger, GSH plays a major role in the detoxification of reactive oxygen species (ROS) and drug metabolites. ${ }^{5}$ When oxidative stress increases, GSH converts into GSSG i.e., it gets oxidized. ${ }^{4}$ In this process, two molecules of GSH form a molecule of GSSG with the formation of double-sulfur bond. ${ }^{5} \mathrm{GSH}$ is converted to GSSG under oxidative stress and can be reverted back to reduced form by the action of the enzyme glutathione reductase (GRx). ${ }^{6}$ It is well known that under oxidative stress, GSH can be converted to GSSG, which results in the impairment of radical scavenging activity and hence, loss of antioxidant activity. ${ }^{6,7} \mathrm{GSH}$ plays a major role in the protection of organs such as liver, intestine, lungs and kidney when they are exposed to xenobiotics. ${ }^{7-9}$ The level of GSH is decreased in many diseases such as alcoholic liver injury, diabetes mellitus, hemolysis and cancer. ${ }^{8,9}$ It is also used for the treatment of many diseased conditions such as chronic renal failure, diabetes, lung inflammation and malnutrition. It is found in blood plasma, produced mainly in the liver in humans, and its concentration is about $2 \mathrm{mg} /$ $\mathrm{mL}$ in plasma. $^{10,11}$

Sheep alpha-2-macroglobulin $(\alpha 2 \mathrm{M})$ is a large glycoprotein of $630 \mathrm{kDa}$ found in the plasma and a homologue of human $\alpha 2 \mathrm{M}$. Like its human counterpart, it is a tetrameric glycoprotein consisting of four identical subunits. The $\alpha 2 \mathrm{M}$ captures a variety of proteinases and is considered as a major proteinase inhibitor in the blood. ${ }^{12,13}$ The $\alpha 2 \mathrm{M}$ plays an important role in innate immunity and is highly conserved throughout evolution. ${ }^{14}$ The $\alpha 2 \mathrm{M}$ possesses a unique trapping mechanism and captures a variety of proteinases both in vitro and in vivo and is considered as a major proteinase inhibitor. This protein traps the proteinases released by cells during inflammation and hence regulates the extracellular proteolytic activity resulting from fibrinolysis and clotting. ${ }^{15}$ It inhibits the proteinases present in the plasma and also protect cells against pathogens since it can also trap proteinases from non-human origin.

In the present study, we explored the interaction of GSH with $\alpha 2 \mathrm{M}$ in the presence of fluorescent light (as well as dark). In this study, our aim was to study the interaction of GSH with $\alpha 2 \mathrm{M}$ and how it affects the anti-proteinase and conformational status of the protein. The binding interaction was explored by using ultraviolet (UV), and fluorescence spectroscopy and isothermal titration calorimetry (ITC). The changes in the secondary structure were analyzed by Fourier-transform infrared spectroscopy (FT-IR).

\section{Materials and methods}

\section{Isolation of $\alpha 2 M$}

Fresh sheep blood was collected from the slaughter house (within minutes of slaughter of animal) for the isolation of $\alpha 2 \mathrm{M}$ from plasma. Sheep $\alpha 2 \mathrm{M}$ was purified by simple two step procedure i.e., ammonium sulphate fractionation and Sephacryl 300HR (Sigma-Aldrich, St. Louis, MO, USA) gel filtration chromatography as reported previously. ${ }^{16}$

\section{Antiproteinase Activity Assay of a2M}

Activity assay of $\alpha 2 \mathrm{M}$ was performed in order to determine the change in the function of native and treated protein as reported previously. ${ }^{12} \alpha 2 \mathrm{M}$ was incubated with varying concentrations of GSH $(20-100 \mu \mathrm{M})$ in the presence and absence of light. A final mixture of $1 \mathrm{~mL}$ was prepared with $50 \mathrm{mM}$ sodium phosphate buffer $\left(\mathrm{pH} 7.4\right.$ ) at $22 \pm 1{ }^{\circ} \mathrm{C}$. After 1 $\mathrm{hr}$ of incubation at room temperature, $100 \mu \mathrm{L}$ of trypsin was added in the reaction mixture for $15 \mathrm{~min}$ at $37{ }^{\circ} \mathrm{C}$. Following incubation, $100 \mu \mathrm{L}$ of soybean trypsin inhibitor (STI) was added for $15 \mathrm{~min}$ at $37^{\circ} \mathrm{C}$. Finally, $2 \mathrm{~mL}$ of N-Benzoyl-DLarginine-p-nitroanilide (BAPNA) was added for $30 \mathrm{~min}$ and absorbance was recorded at $410 \mathrm{~nm}$. GSH, trypsin, STI and BAPNA were obtained from Sigma-Aldrich.

\section{$U V$-visible Absorption Spectroscopy}

To analyze the changes in the native conformation of protein, the UV absorbance spectra were recorded. ${ }^{17}$ Ten $\mu \mathrm{M}$ of $\alpha 2 \mathrm{M}$ was incubated with varying concentration of glutathione $(20-100 \mu \mathrm{M})$ in absence and presence of light. The absorption spectrum was recorded in the range of 250 $350 \mathrm{~nm}$ on a Shimadzu UV mini visible spectrophotometer UV-1700.

\section{Fluorescence Spectroscopy}

Intrinsic fluorescence was performed to analyze the change in the structure of $\alpha 2 \mathrm{M}$ after its interaction with glutathione. a2M was incubated with increasing concentrations of glutathione $(20-100 \mu \mathrm{M})$ in dark as well as in the presence of light and were recorded on a Shimadzu RF-5301 spectrofluorophotometer (Shimadzu, Tokyo, Japan) in the range of 300-400 $\mathrm{nm}$ in a quartz cell of path length $10 \mathrm{~nm}$. The final concentration of protein was $10 \mu \mathrm{M} \cdot .^{15,17}$

\section{FT-IR Spectroscopy}

Another technique which was used to study the secondary structural changes in the native structure of protein was FT-IR. ${ }^{18,19}$ FT-IR spectra were recorded in the range of $1600-1700 \mathrm{~cm}^{-1}$ at room temperature $\left(22 \pm 1^{\circ} \mathrm{C}\right)$ sodium 
phosphate buffer ( $\mathrm{pH} 7.4$ ). Ten $\mu \mathrm{M}$ of $\alpha 2 \mathrm{M}$ was incubated with increasing concentrations of glutathione (50-100 $\mu \mathrm{M})$ and were recorded on a Perkin Elmer FT-IR Spectrum 100 (Perkin Elmer, Waltham, MA, USA).

\section{Isothermal Titration Calorimetry (ITC)}

To study the thermodynamics signatures for binding of GSH with the protein, isothermal titration calorimetry (ITC) was performed. Enthalpy, entropy, binding sites and Gibbs free energy of $\alpha 2 \mathrm{M}$-glutathione interaction were determined on a VP-ITC titration microcalorimetry system (MicroCal, Northampton, MA, USA) as reported previously. ${ }^{19}$ Previous studies have shown that the change in enthalpy and entropy for protein-ligand interaction may reveal the binding forces involved in the interaction. ${ }^{20-22}$ If the value of $\Delta \mathrm{S}$ and $\Delta \mathrm{H}$ are negative, then Van der Walls and hydrogen bond formation are involved in the interaction and if both are found to be positive, it suggests hydrophobic interaction. ${ }^{22}$ The concentration of the $\alpha 2 \mathrm{M}$ in the sample cell was $10 \mu \mathrm{M}$, and the syringe was loaded with $20 \mu \mathrm{M} \mathrm{GSH}$, while the reference cell was filled with $50 \mathrm{mM}$ sodium phosphate buffer ( $\mathrm{pH}$ 7.4). The sample was continuously stirred at $307 \mathrm{rpm}$ and reference power was kept at $16 \mu \mathrm{cal} \mathrm{sec}^{-1}$. The heat of dilution was determined by control experiments and subtracted from the integrated data before curve fitting. The ORIGIN ${ }^{\circledR}$ software (OriginLab Corporation, Northampton, MA, USA) was used to analyze the titration curves. $^{23}$

\section{Results}

\section{The Antiproteinase Activity of $22 M$}

Activity assay was performed to study the functional change in the native protein. Figure $1 \mathrm{~A}$ showed the activity profile of treated $\alpha 2 \mathrm{M}$ in dark and Figure 1B depicts antiproteinase activity in the presence of light. Loss in antiproteinase activity at $100 \mu \mathrm{M}$ GSH was $18 \%$ under dark and $38 \%$ when it was photoilluminated either due to change in the conformational status of the protein or oxidative damage to the bait region amino acids.

\section{UV-visible Absorption Spectroscopy Results}

UV-visible spectra were analyzed in order to check the possible change in the conformational status of protein as well possible complex formation between protein and ligand. $\alpha 2 \mathrm{M}$ showed a peak at around $278 \mathrm{~nm}$ which was due to the presence of three aromatic amino acid residues (tryptophan, tyrosine and phenylalanine). Figure 2A showed
A.

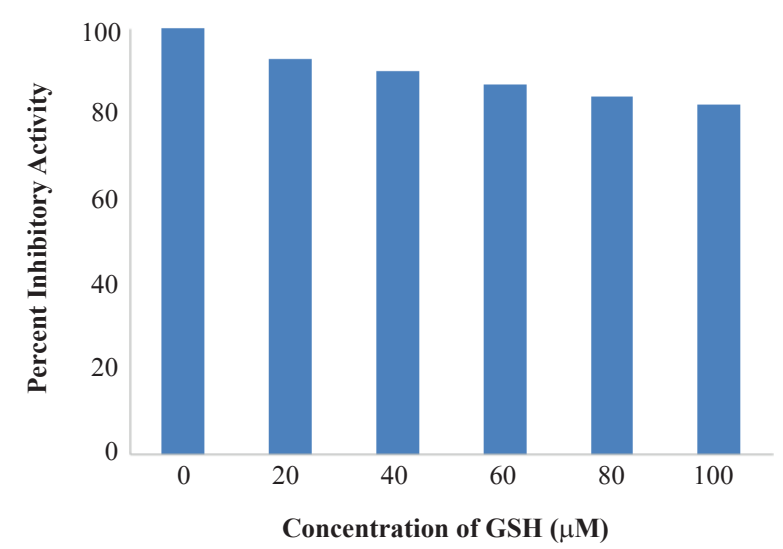

B.

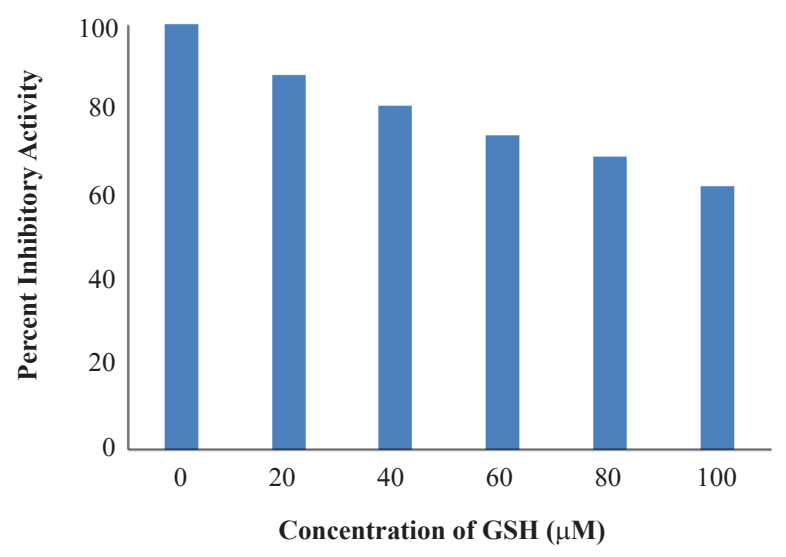

Figure 1. Percent inhibitory activity of $\alpha 2 \mathrm{M}$. A: $\alpha 2 \mathrm{M}$ was incubated with increasing concentration of GSH in dark then assayed for antiproteolytic activity; B: $\alpha 2 \mathrm{M}$ was incubated with increasing concentration of GSH in visible light then assayed for antiproteolytic activity.

the UV visible spectra of $\alpha 2 \mathrm{M}$ with increasing concentration of GSH in dark. Increasing the concentration of GSH leads to an increase in UV absorbance which suggests the possibility of complex formation between GSH and $\alpha 2 \mathrm{M}$. The interaction of $\alpha 2 \mathrm{M}$ was also analyzed with GSH in the presence of white flourescent light. As shown in Figure 2B, GSH causes a dose dependent decrease in absorbance and the peak shifts to higher wavelength in presence of light. At the highest GSH concentration $(100 \mu \mathrm{M})$, there was a hyperchromic shift (about 2\%) in dark and a hypochromic shift (about 2\%) in the presence of light suggesting a change in the polarity around tryptophan residues and hydrophobicity thereby inferring that GSH induces a conformational change in the native protein. Figure $2 \mathrm{C}$ showed the comparative UV absorption spectra of $\alpha 2 \mathrm{M}$ alone and with GSH in the presence of white light and dark at $100 \mu \mathrm{M}$. 

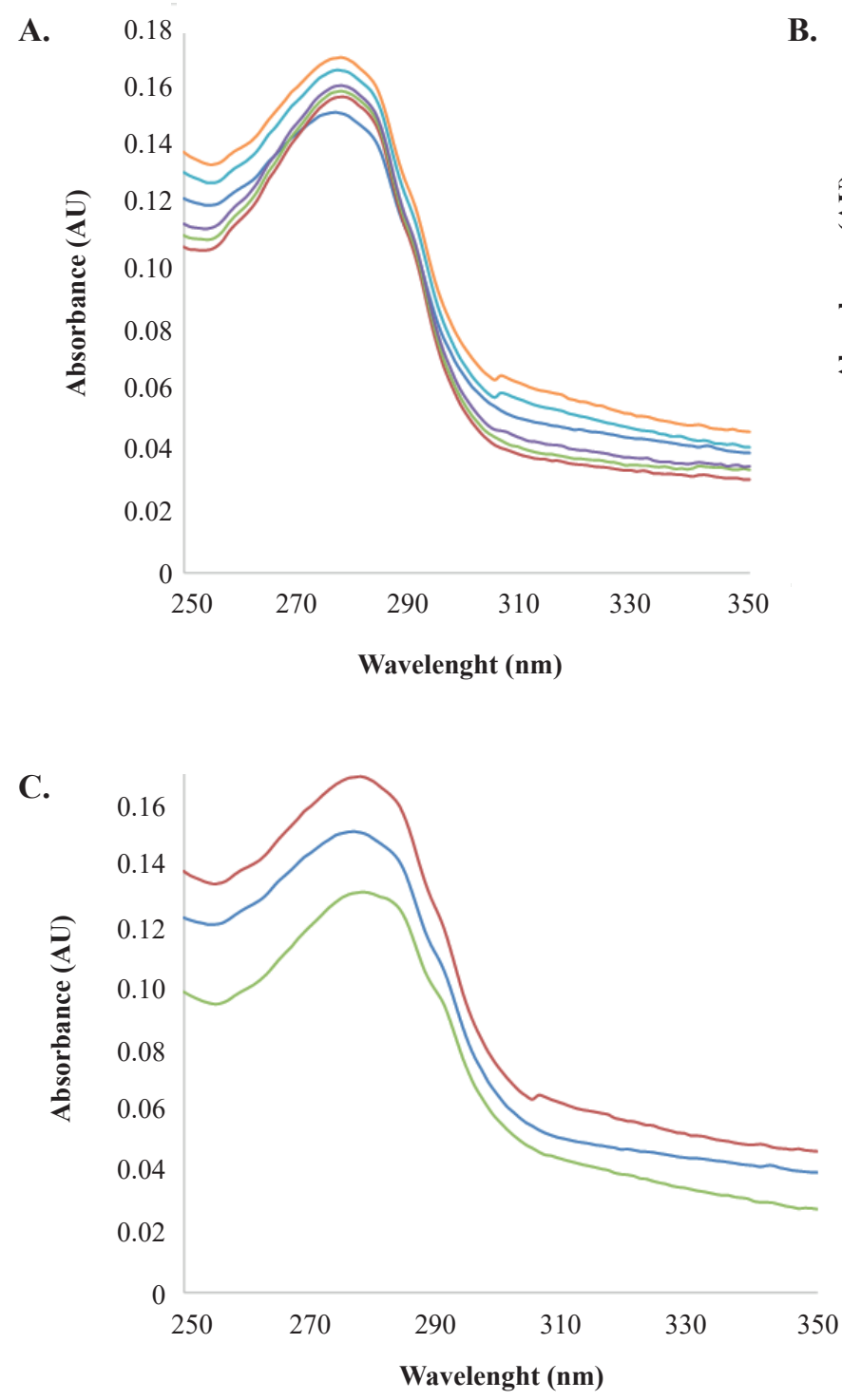

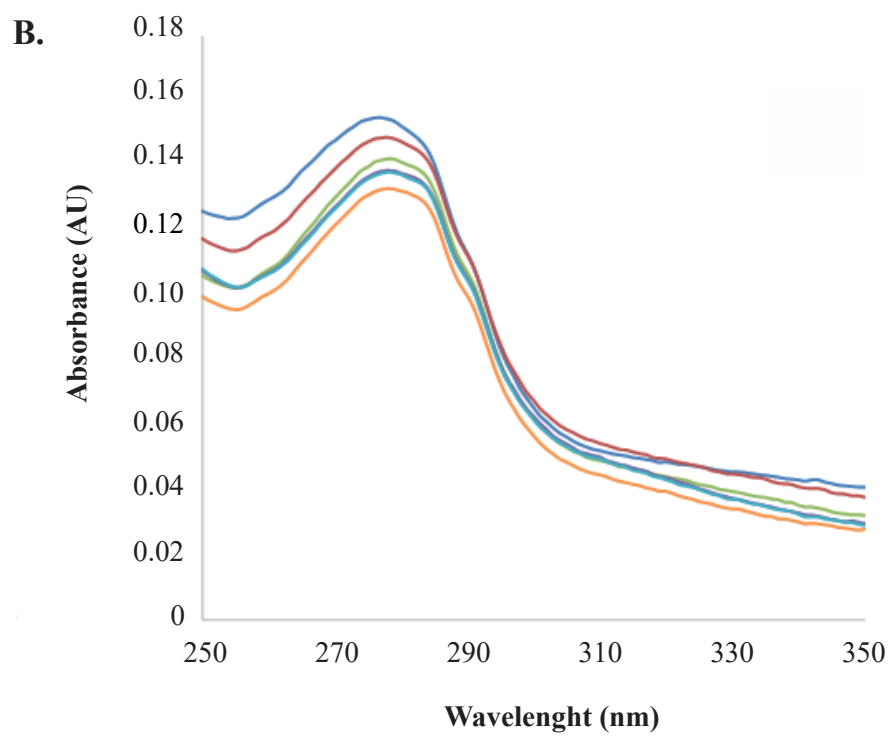

Figure 2. The absorbance result of UV spectroscopy. A: $\alpha 2 \mathrm{M}$ was incubated with increasing concentration of GSH in dark; B: $\alpha 2 \mathrm{M}$ was incubated with increasing concentration of GSH in visible white light; C: comparative UV spectra of $\alpha 2 \mathrm{M}$ and with GSH in the presence of white light and dark at $100 \mu \mathrm{M}$.

\section{Intrinsic Fluorescence Measurements}

Intrinsic fluorescence was a useful technique utilized to identify the conformational changes in the native structure of proteins. Intrinsic fluorescence of the protein was mainly depend upon the aromatic amino acid residues i.e., tyrosine, phenylalanine and tryptophan but in $\alpha 2 \mathrm{M}$, tryptophan played a major role. Upon increasing the concentration of ligand, fluorescence of native protein gradually decreased. Figure $3 \mathrm{~A}$ showed the intrinsic fluorescence pattern of $\alpha 2 \mathrm{M}$ with varying concentration of GSH $(20-100 \mu \mathrm{M})$ in dark. Native $\alpha 2 \mathrm{M}$ showed a peak at $329 \mathrm{~nm}$ and the intensity decreasesd upon increasing the dose of GSH. At $100 \mu \mathrm{M}$, there was maximum fluorescence quenching with a shift of peak (1 $\mathrm{nm}$ ) suggesting a possible change in the microenvironment around the chromophore of $\alpha 2 \mathrm{M}$. Similar results were obtained when photo-illuminated GSH was incubated with $\alpha 2 \mathrm{M}$, although there was a minor increase in quenching in the presence of light (Figure 3B and Figure 3C).

\section{FT-IR Spectroscopy Results}

FT-IR spectroscopy was employed to study the change in the secondary structure of protein. Amide I band was analysed as it was the most important band in protein used for the analysis of the possible structural change. Amide I band displayed in the wave number range $1600-1700 \mathrm{~cm}^{-1}$ which was governed by the stretching of the $\mathrm{C}=\mathrm{O}(70-85 \%)$ and minor contribution of C-N groups (10-20\%). Amide I band for native $\alpha 2 \mathrm{M}$ was centered at around $1635 \mathrm{~cm}^{-1}$ which was characteristic of $\beta$-sheet structure. FT-IR spectroscopy was 

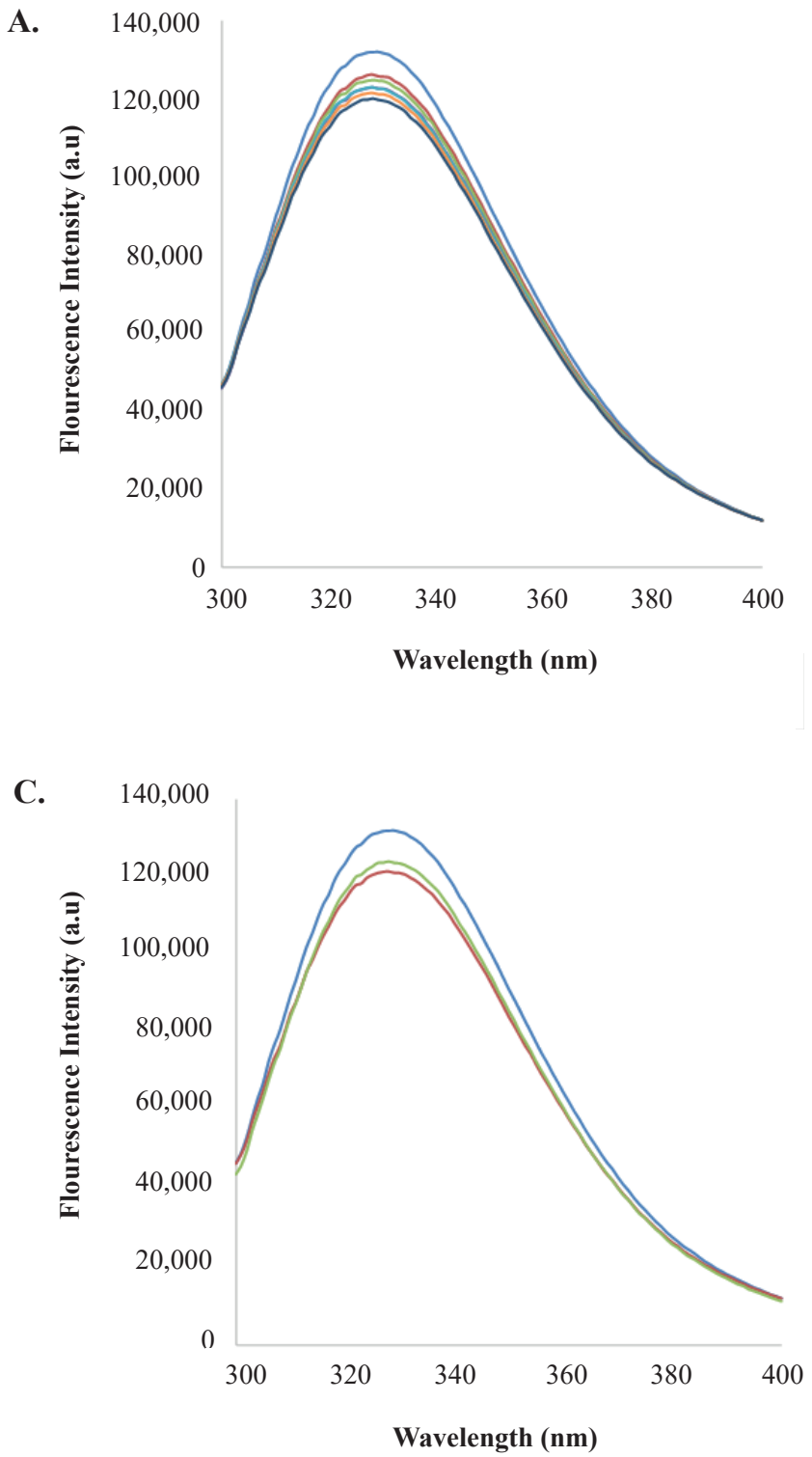

utilized to study the structural changes in the protein after its interaction with GSH interaction in dark and light. FTIR spectra for native $\alpha 2 \mathrm{M}$ and co-incubation with varying concentration of GSH $(50-100 \mu \mathrm{M})$ were recorded in the range of 1600-1700 $\mathrm{cm}^{-1}$. Figure 4A showed FT-IR spectra of native $\alpha 2 \mathrm{M}$, the amide I band was located at $1635 \mathrm{~cm}^{-1}$ which confirmed the presence of predominant $\beta$-sheet structure in $\alpha 2 \mathrm{M}$. At $50 \mu \mathrm{M}$ GSH, there was a slight decrease in intensity which was more pronounced at $100 \mu \mathrm{M}$ GSH concentration suggesting loss in the $\beta$-sheet content of the protein. Figure $4 \mathrm{~B}$ depicted the $\alpha 2 \mathrm{M}$-glutahione interaction curve in the presence of visible fluorescent light. At $50 \mu \mathrm{M}$ of $\mathrm{GSH}$, a band observed at $1635 \mathrm{~cm}^{-1}$ confirmed the decrease in the $\beta$-sheet content of $\alpha 2 \mathrm{M}$ as in the previous case. At

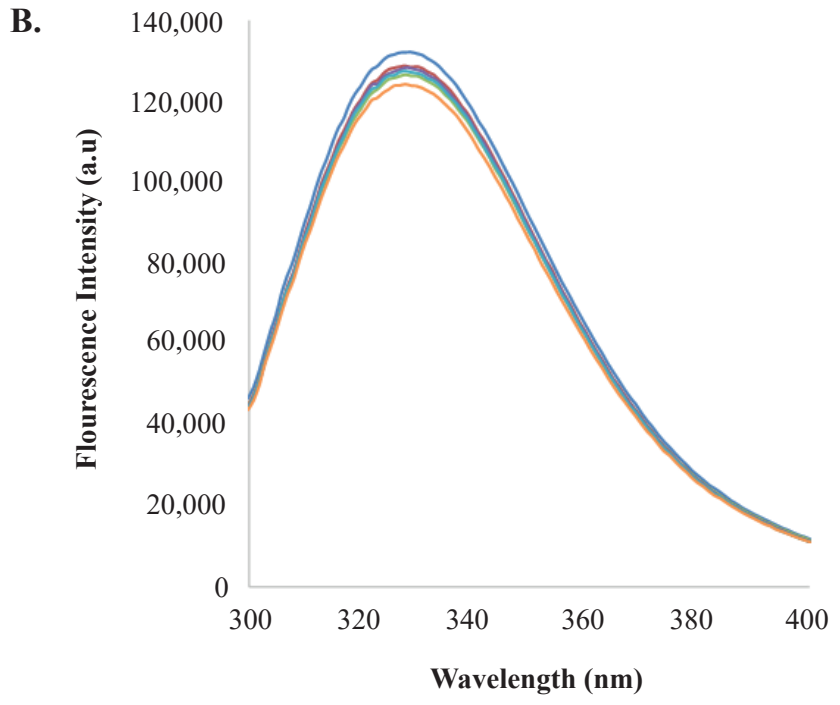

Figure 3. The fluorescence intensity of the spectroscopy. A: fluorescence spectra of native $\alpha 2 \mathrm{M}$ and GSH in dark; B: fluorescence spectra of a2M exposed to GSH in fluorescent white light; $\mathrm{C}$ : comparative spectra of $\alpha 2 \mathrm{M}$ and with GSH $(100 \mu \mathrm{M})$ in dark and in the presence of white light.

$100 \mu \mathrm{M}$ GSH, there was a shift of peak and new band was observed at $1640 \mathrm{~cm}^{-1}$ which suggests subtle perturbation in the secondary structure of the protein upon its exposure to photo-illuminated GSH, not observed in dark.

\section{ITC Results}

To understand the $\alpha 2 \mathrm{M}$-glutathione interaction, its thermodynamics parameters were determined by ITC. ITC was used to determine the change in entropy $(\Delta S)$, enthalpy $(\Delta \mathrm{H})$, stoichiometry of binding, and Gibbs free energy $(\Delta \mathrm{G})$. Figure 5 showed the titration profile of $\alpha 2 \mathrm{M}$-glutahione binding which suggests the binding was exothermic in nature. The data obtained through ITC showed the change in enthalpy and entropy and was found 
A.

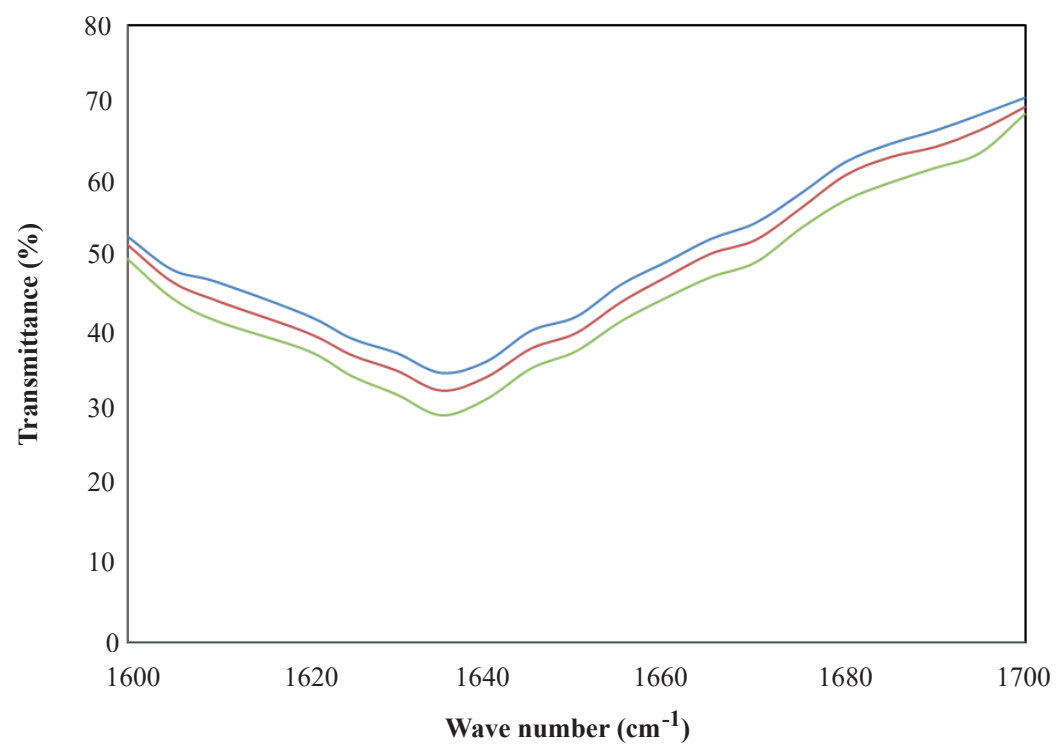

B.

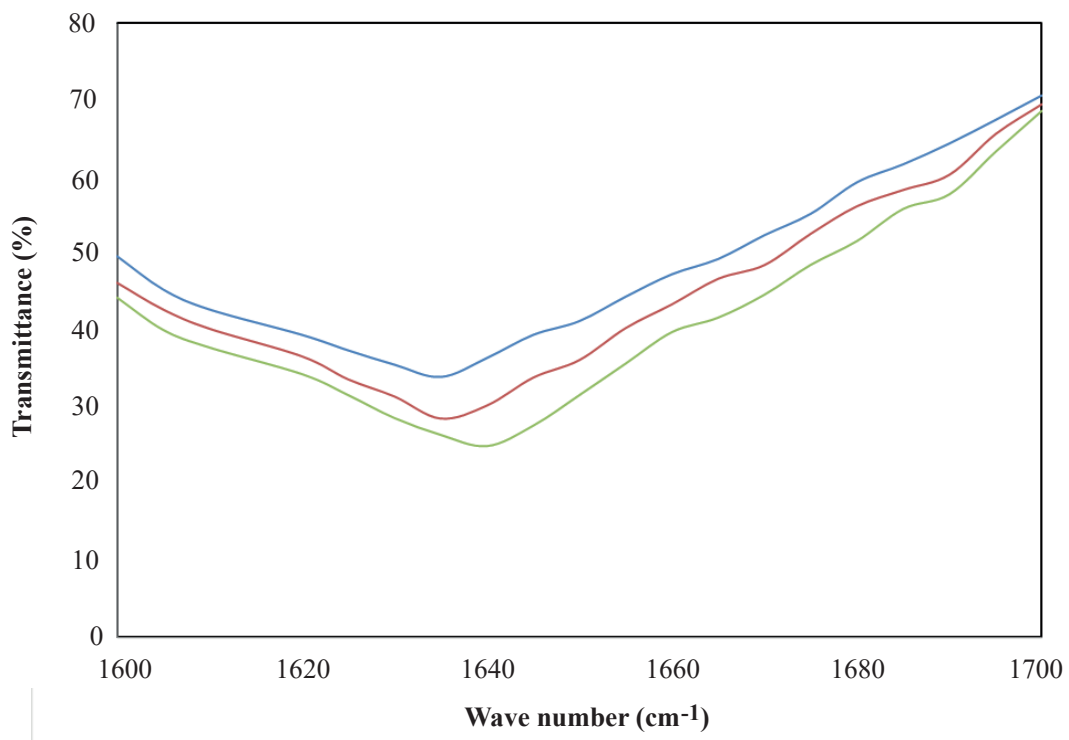

Figure 4. The percentage of transmitance of FT-IR Spectroscopy. A: FT-IR spectra of native $\alpha 2 \mathrm{M}$ and GSH treated in dark; B: FT-IR spectra of native $\alpha 2 \mathrm{M}$ and GSH treated in the presence of white light. to be negative and was shown in Table 1. VPC-ITC Micro

$\mathrm{Cal}$ was used to determine the binding energetic such as entropy (S), enthalpy $(H)$, Gibbs free energy change $(\mathrm{G})$, stoichiometry of binding sites $(\mathrm{N})$ and binding affinity $(\mathrm{Kb})$ of $\alpha 2 \mathrm{M}-\mathrm{GSH}$ interaction. The negative values of $\Delta \mathrm{H}(-$ $1.594 \times 104$ joulemol-1) and $\Delta \mathrm{S}(-5.34 \times 104$ joulemol-1) indicated that the interaction process was exothermic and possibly involved hydrogen bonds. Moreover, the negative value of $\Delta \mathrm{G}$ (-2.68 kjoulemol-1) signified the reaction to be spontaneous and thermodynamically favourable. The stoichiometry of binding/number of binding sites $(\mathrm{N})$ was found to be around 1.38. The change in enthalpy and entropy for protein-ligand interaction may reveal the binding forces involved in the interaction. If the value of $\Delta \mathrm{S}$ and $\Delta \mathrm{H}$ are negative, then Van der Walls and hydrogen bond formation were involved in the interaction and if both were positive, then it suggested hydrophobic interaction. The negative value for $\Delta \mathrm{S}$ and $\Delta \mathrm{H}$ observed in $\alpha 2 \mathrm{M}-\mathrm{GSH}$ interaction suggests it was enthalpy driven and involves hydrogen bonding and Van der Walls forces.

\section{Discussion}

This is the first study to explore the interaction of GSH with $\alpha 2 \mathrm{M}$, a plasma antiproteinase and major zinc binding protein. The primary aim of this study is to explore the possible interaction between GSH and $\alpha 2 \mathrm{M}$. Fluorescence transform infra-red spectroscopy technique was employed to study the secondary structural changes in the native form of protein. ${ }^{18,19}$ FT-IR spectroscopy was utilized to study the 


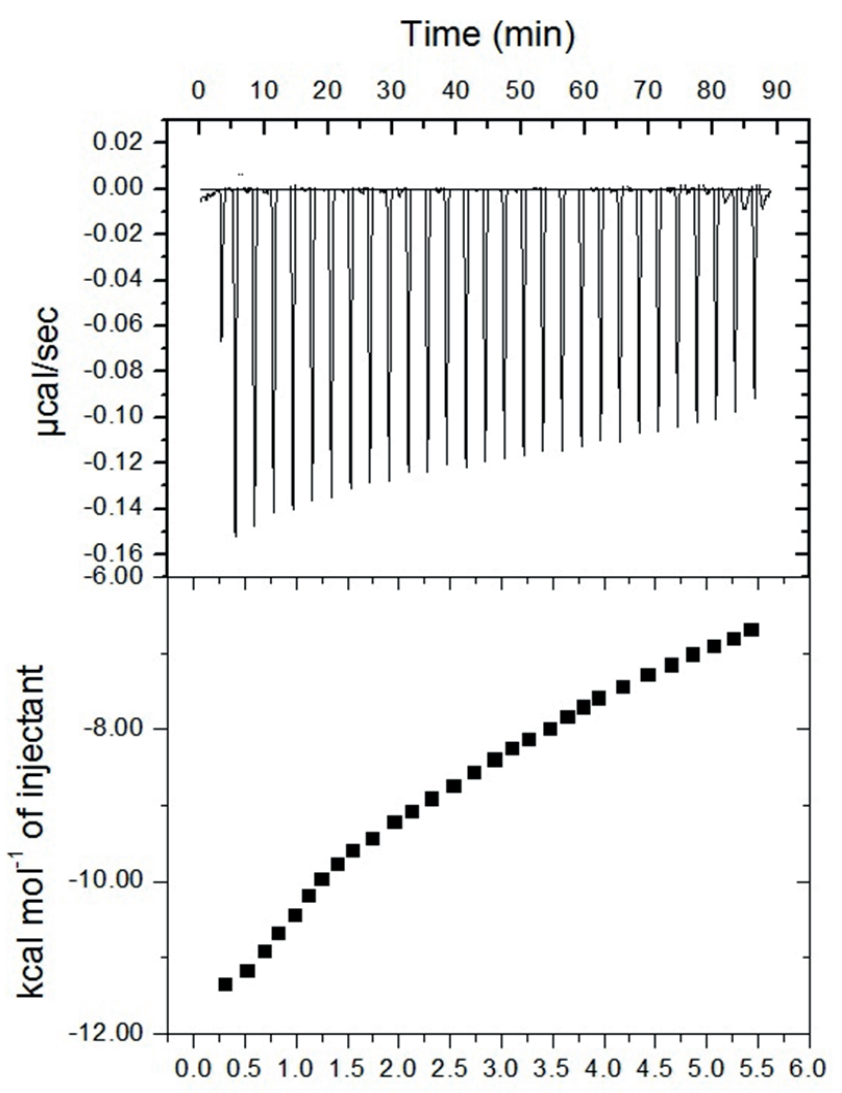

Figure 5. Isothermal titration calorimetry profile of $\boldsymbol{\alpha 2 M}$-glutathione. Titration of $\alpha 2 \mathrm{M}(2 \mu \mathrm{M})$ with GSH (20 $\mu \mathrm{M})$ at $\mathrm{pH} 7.5$ shows calorimetric response as consecutive injection of ligand is added to the sample cell.

structural changes in the protein after its interaction with GSH in dark and light. The FT-IR spectra of native $\alpha 2 \mathrm{M}$ confirms the presence of predominant $\beta$-sheet structure in $\alpha 2 \mathrm{M}$. At $50 \mu \mathrm{M}$ GSH, there was a slight decrease in intensity which was more pronounced at $100 \mu \mathrm{M}$ GSH concentration suggesting loss in the $\beta$-sheet content of the protein. At $50 \mu \mathrm{M} \mathrm{GSH}$, a band observed at $1635 \mathrm{~cm}^{-1}$ confirms the decrease in the $\beta$-sheet content of $\alpha 2 \mathrm{M}$ as in the previous case. At $100 \mu \mathrm{M}$ GSH, there is a shift of peak and new band was observed at $1640 \mathrm{~cm}^{-1}$ which suggests subtle perturbations in the secondary structure of the protein due to photo-illumination of GSH, which was not observed in dark. Previous studies have shown that the changes in enthalpy and entropy for protein-ligand interaction may reveal the binding forces involved in the interaction. ${ }^{20-22}$ If the value of $\Delta \mathrm{S}$ and $\Delta \mathrm{H}$ are negative, then Van der Walls and hydrogen bond formation are involved in the interaction and if both are found to be positive, it suggests hydrophobic interaction. ${ }^{22}$ The negative values for $\Delta \mathrm{S}$ and $\Delta \mathrm{H}$ observed in $\alpha 2 \mathrm{M}-\mathrm{GSH}$ interaction suggests it was enthalpy driven and involves hydrogen bonding and Van der Walls forces. ${ }^{22,23}$

GSH, a principle thiol-containing tripeptide, is an intracellular antioxidant which plays a major role as an antioxidant in cellular defence against free radicals and other harmful oxidants. It is a ubiquitous molecule and provides defence against free radicals, hydroperoxides and other harmful oxidants. However, its production declines with age, and is often given orally or administered intravenously ${ }^{24-26}$, which causes its increased plasma concentration. Our studies show that incubation of $\alpha 2 \mathrm{M}$ with GSH (20-100 $\mu \mathrm{M})$ results in loss of functional status of this antiproteinase. This loss in activity is more pronounced when GSH $(20-100 \mu \mathrm{M})$ is photoilluminated, resulting in secondary structural changes in the protein. This change in conformation of protein might occur due to either perturbation or disturbance induced in the protein by GSH binding or oxidation of some essential amino acids. ${ }^{27}$ This study assumes importance as long term administration of GSH leads to zinc deficiency since $\alpha 2 \mathrm{M}$ is a major zinc binding protein in the plasma. ${ }^{16,27}$

\section{Conclusion}

Our studies show that incubation of $\alpha 2 \mathrm{M}$ with $\mathrm{GSH}$ results in loss of functional status of the antiproteinase and is more pronounced when GSH is photoilluminated resulting in secondary structural changes in the protein. This change in conformation of $\alpha 2 \mathrm{M}$ may be due to either perturbation or damage induced in the protein by GSH binding or oxidation of some essential amino acids.

Table 1. Binding and thermodynamic parameters for the interaction of bilirubin with $\alpha 2 \mathrm{M}$ obtained by ITC experiment at $37^{\circ} \mathrm{C}$.

\begin{tabular}{lc}
\hline \multicolumn{1}{c}{$\begin{array}{c}\text { Thermodynamic } \\
\text { Parameters }\end{array}$} & Values \\
\hline $\mathrm{N}$ & 1.38 \\
$\mathrm{~K}_{\mathrm{b}}\left(\mathrm{M}^{-1}\right)$ & $1.42 \times 10^{4}$ \\
$\Delta \mathrm{H}\left(\right.$ joulemol $\left.^{-1}\right)$ & $-1.594 \times 10^{7}$ \\
$\mathrm{~T} \Delta \mathrm{S}\left(\right.$ joulemol $\left.^{-1}\right)$ & $-5.34 \times 10^{4}$ \\
$\Delta \mathrm{G}_{\left(\text {kjoulemol }^{-1}\right)}$ & -2.68 \\
\hline
\end{tabular}

Note: $\mathrm{N}$ is the stoichiometry of binding, $\mathrm{Kb}$ is the binding constant, $\Delta \mathrm{H}$ is the change in enthalpy, $\Delta \mathrm{S}$ is the change in entropy, and $\Delta \mathrm{G}$ is the change in Gibbs free energy. 


\section{Acknowledgements}

The authors are grateful to the Department of Biochemistry, Aligarh Muslim University, Aligarh for the facilities provided. The University Grants Commission (UGC), New Delhi is also acknowledged for financial support. The authors wish to thank the reviewer(s) for their perception, suggestions and recommendations.

\section{References}

1. Wang Q, Guan Y, Yang M. Application of superparamagnetic microspheres for affinity adsorption and purification of glutathione. J Magnet Magnetic Material. 2012; 324(20): 3300-5.

2. Meister A, Anderson ME. Glutathione. Ann Rev Biochem. 1983; 52: 711-60.

3. Noctor G, Gomez L, Vanacker H, Foyer CH. Interactions between biosynthesis, compartmentation and transport in the control of glutathione homeostasis and signalling. J Exp Bot. 2002; 53(372): 1283-304.

4. Noh HB, Chandra P, Moon JO, Shim YB. In vivo detection of glutathione disulfide and oxidative stress monitoring using a biosensor. Biomaterials. 2012; 33(9): 2600-7.

5. Chen J, He Z, Liu H, Cha C. Electrochemical determination of reduced glutathione (GSH) by applying the powder microelectrode technique. J Electroanal Chem. 2006; 588(2): 324-30.

6. Pastore A, Federici G, Bertini E, Piemonte F. Analysis of glutathione: implication in redox and detoxification. Clin Chim Acta. 2003; 333(1): 19-39.

7. DeLeve LD, Kaplowitz N. Glutathione metabolism and its role in hepatotoxicity. Pharmacol Ther. 1991; 52(3): 287-305.

8. Flagg EW, Coates RJ, Jones DP, Byers TE, Greenberg RS, Gridley G, et al. Dietary glutathione intake and the risk of oral and pharyngeal cancer. Am J Epidemiol. 1994; 139(5): 453-65.

9. Lu SC. Regulation of glutathione synthesis. Mol Asp Med. 2009; 30(1-2): 42-59.

10. Gate L, Vauthier C, Couvreur P, Tew KD, Tapiero H. Glutathioneloaded poly (isobutylcyanoacrylate) nanoparticles and liposomes: Comparative effects in murine erythroleukæmia and macrophagelike cells. STP Pharma Sci. 2001; 11(5): 355-61.

11. Camera E, Picardo M. Analytical methods to investigate glutathione and related compounds in biological and pathological processes. J Chromatography B. 2002; 781(1-2): 181-206.

12. Ganrot PO. The combining ratio between trypsin and serum alpha-2- macroglobulin. Acta Chem Scand. 1966; 20(8): 2299-300.

13. Barrett AJ, Starkey PM. The interaction of $\alpha 2$-macroglobulin with proteinases. Characteristics and specificity of the reaction, and a hypothesis concerning its molecular mechanism. Biochem J. 1973; 133(4): 709-24.

14. Wyatt AR, Kumita JR, Farrawell NE, Dobson CM, Wilson MR. Alpha2-macroglobulin is acutely sensitive to freezing and lyophilization: Implications for structural and functional studies. PLoS One. 2015; 10(6): e0130036. doi: 10.1371/journal.pone.0130036.

15. Rehman AA, Ahsan H, Khan FH. Alpha-2-macroglobulin: a physiological guardian. J Cell Physiol. 2013; 228(8): 1665-75.

16. Khan FH, Mirza M, Saleemuddin M. Caprine alpha-2-macroglobulin contains thiolesters of unequal reactivity. J Biochem Mol Biol Biophy. 1999; 3: 109-16.

17. Ali SS, Zia MK, Siddiqui T, Khan FH. Binding interaction of sheep alpha-2-macroglobulin and tannic acid: A spectroscopic and thermodynamic study. Spectrochim Acta Part A: Mol Biomol Spect. 2018; 204: 748-53.

18. Siddiqui T, Zia MK, Ali SS, Ahsan H, Khan FH. Inactivation of alpha2-macroglobulin by photo-illuminated gallic acid. J Fluores. 2019; 29(4): 969-79.

19. Hu YJ, Liu Y, Wang JB, Xiao XH, Qu SS. Study of the interaction between monoammonium glycyrrhizinate and bovine serum albumin. J Pharma Biomed Anal. 2004; 36(4): 915-19.

20. Rehman AA, Sarwar T, Arif H, Ali SS, Ahsan H, Tabish M, et al. Spectroscopic and thermodynamic studies on ferulic acid-alpha-2macroglobulin interaction. J Mol Struct. 2017; 1144: 254-9.

21. Tao WS, Li W, Jiang YM. Protein Molecular Basic. Beijing: The People's Education Press; 1981.

22. Cui FL, Fan J, Li JP, Hu ZD. Interactions between 1-benzoyl-4-pchlorophenyl thiosemicarbazide and serum albumin: investigation by fluorescence spectroscopy. Bioorg Med Chem. 2004; 12(1): 151-7.

23. Zia MK, Siddiqui T, Ali SS, Ahsan H, Khan FH. Understanding the binding interaction between methotrexate and human alpha2-macroglobulin: Multi-spectroscopic and computational investigation. Arch Biochem Biophys. 2019; 675: 108118. doi: 10.1016/j.abb.2019.108118.

24. Dröge W, Breitkreutz R. Glutathione and immune function. Proc Nutr Soc. 2000; 59(4): 595-600.

25. Smeyne M, Smeyne RJ. Glutathione metabolism and Parkinson's disease. Free Rad Biol Med. 2013; 62: 13-25.

26. Schmitt B, Vicenzi M, Garrel C, Denis FM. Effects of N-acetylcysteine, oral glutathione (GSH) and a novel sublingual form of GSH on oxidative stress markers: A comparative crossover study. Redox Biol. 2015; 6: 198-205.

27. Skene K, Walsh SK, Okafor O, Godsman N, Barrows C, Meier P, et al. Acute dietary zinc deficiency in rats exacerbates myocardial ischaemia-reperfusion injury through depletion of glutathione. Brit J Nutr. 2019; 121(9): 961-73. 